\title{
Mammographic and sonographic spectrum of non-puerperal mastitis
}

\author{
M.H. Lequin*a, J. van Spengler ${ }^{\mathrm{a}}$, R. van Pel $^{\mathrm{b}}$, C. van Eijck $^{\mathrm{c}}$, H. van Overhagen ${ }^{\mathrm{a}}$ \\ 'Department of Diagnostic Radiology. University Hospital Rotterdam-Dijkzigt, Dr Molewaterplein 40, 3015 GD Rotterdam. The Netherlands \\ 'Department of Pathology, St. Franciscus Gasthuis, Kleiweg 500, 3045 PM Rotterdam, The Netherlands \\ 'Department of Siurgery, University Hospital Rotterdam-Dijkzigt, Dr Molewaterplein 40, 3015 GD Rotterdam, The Netherlands
}

Received 24 August 1995; revision 4 September 1995; accepted 8 September 1995

\begin{abstract}
The goal of this study was to explore possible specific mammographic and sonographic features in women with non-puerperal mastitis (NPM), in order: to make an accurate diagnosis and prevent unnecessary surgical procedures. From a group of 93 patients with NPM diagnosed between 1987 and 1992, the mammograms of 41, the sonograms and cytology of 47, and the histology of seven patients were retrospectively reviewed. Follow-up was performed on those without histology. In 20 of the 47 patients the inflammation was located subareolarly. In $50 \%$ of those with non-subareolar lesions, mammography showed a circumscribed lesion. Sonographically, all patients had an identifiable lesion either well or poorly defined. The majority of the lesions were cystic, but in 23 of 47 cases solid components were seen. Signs of infection in cystic lesions were observed in 25 of 47 cases. Posterior shadowing was not observed. During the follow-up period no breast malignancy was found. It is concluded that NPM has no specific mammographic or sonographic sign. Diagnosis should be made with additional diagnostic assessment, such as FNAB, which was diagnostic in all cases.
\end{abstract}

Keywords: Breast, radiography; Breast, disease; Radiography, breast

\section{Introduction}

The diagnosis of inflammatory disease of the lactating breast is usually made on clinical signs and symptoms. Inflammation of the non-lactating breast occurs less frequently and is more difficult to recognize, because the clinical signs are not sprecific. Most patients present with a mass in the breast without any other sign of inflammation. Non-puerperal mastitis (NPM) does not need surgery to be cured and recognizing this entity is therefore important because a correct diagnosis will prevent unnecessary surgical procedures.

In order to explore the specific diagnostic features

* Corresponding author, Tel.: +31 104633379 ; Fax: +3110463 4033. that may help to diagnose NPM before surgical measures are taken, we reviewed the mammographic and sonographic spectrum of women with proven NPM of the breast.

\section{Patients and methods}

Between 1987 and 1992, 93 patients with acute inflammation of non-lactating breasts were diagnosed in our hospital. Thirty-nine had breast surgery or biopsies prior to radiologic studies, in seven patients the interval between the radiologic and pathologic examinations was more than 3 months; subsequently, these 46 patients were not included in the study. Mammography, sonography, histology and cytology of the remaining 47 patients were retrospectively reviewed and the results 
were documented. The patients were aged between 15.0 and 69.1 (median, 40.0) years.

Mammography was performed in 41 patients using a dedicated breast unit (CGR Sonograph $550 \mathrm{~T}$ ) with a rotating molybdenum anode and a $0.3-\mathrm{mm}$ focal spot. Descriptive features of breast lesions included location, shape, contour, size, halos, skin thickening, nipple retraction and microcalcifications. Mammography was not performed in six patients younger than 30 years of age with a palpable mass, they underwent ultrasound and ultrasound-guided fine needle aspiration biopsy (FNAB) [1]. Sonography was performed in all patients with a $7.5-\mathrm{MHz}$ linear-array transducer (Aloka SSD650, Tokyo, Japan). The descriptive sonographic features of each lesion included location, shape, contour, size, echogenicity, sound attenuation and the presence of ductectasia.

All 47 patients underwent FNAB with a 23-gauge needie [2]. The cytologic smears were air dried for $10 \mathrm{~min}$ and stained by May-Grünwald-Giemsa methods. Cytological findings were suggestive of inflammation or benignancy in all patients; however, in seven patients a surgical excision-biopsy of the lesion was still done, because based on the clinical and the radiological findings, a malignant tumor could not be excluded. When histology is considered the gold standard for the final diagnosis of NPM, follow-up was done in the remaining patients in order to ensure that on the longer term malignancy was excluded. Mammography was repeated in 13 cases after a median of 126 weeks (range, 9.4-401 weeks). Mammography combined with sonography was performed in 10 cases after a median of 121.3 weeks (range, 14-307 weeks). Sonography alone was done after a median of 43.1 weeks (range, 17.3-57.9). The remaining 14 patients were followed clinically after a median of 158 weeks (range, 85.9-390).

\section{Results}

\subsection{Age and location}

All patients presented with a palpable mass, except one who presented with pruritus of the breast. In 20 women aged between 15.0 and 59.9 years (median, 38.5) the inflammation was located subareolarly. The next most frequent location was the lateral upper quadrant of the breast (Fig. 1). The age range of the women with a breast inflammation not in the subareolar position was between 19.1 and 69.1 years (median, 43.2).

\subsection{Mammography}

Mammographic findings are shown in Table 1. A circumscript lesion was observed in 17 of 41 patients. The size of the lesions ranged between 1.0 and $5.0 \mathrm{~cm}$ (median, 2.0). Poorly defined borders were observed most frequently (Fig. 2a). A halo sign was observed when the borders were well-defined. Skin thickening was seen in
SONOGRAPHY
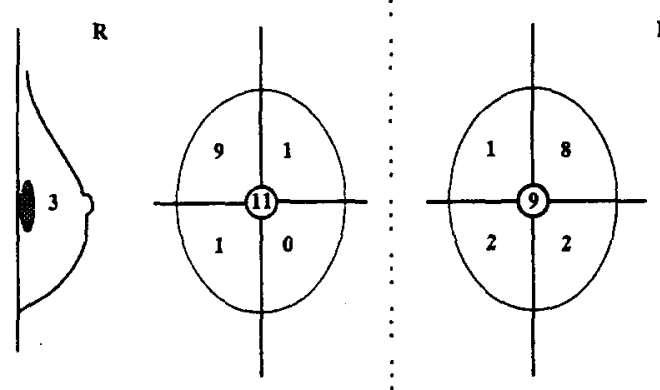

$\mathbf{L}$

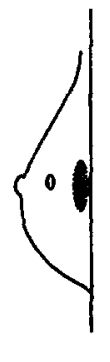

MAMMOGRAPHY
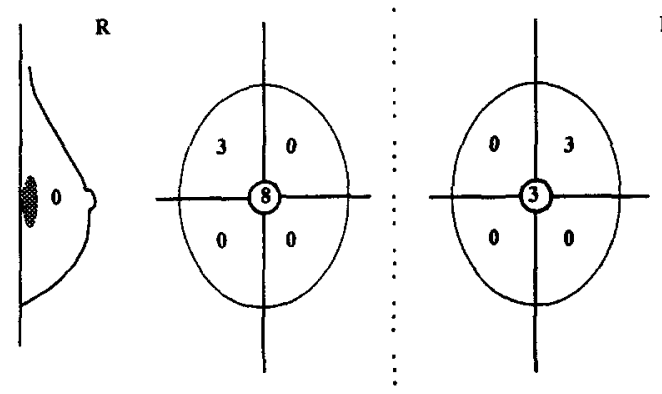

$\mathbf{L}$

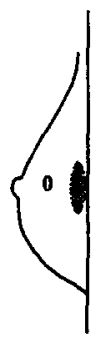

Fig. 1. Schematic presentation of the location of non-puerperal mastitis on mammography and sonography.

seven and nipple retraction in two patients. Only one patient had 'benign' calcifications in the affected breast.

In the remaining 24 patients mammography showed no circumscript breast lesion. In 19 patients no paremchymal pattern abnormality was found; in 11 of these probably due to the presence of very dense fibroglandular tissue (median age, 43.1 years).

Table 1

Mammographic findings of 41 patients with non-puerperal mastitis

\begin{tabular}{lc}
\hline Lesion & No. of cases \\
\hline Circumscript $(n=17)$ & 10 \\
Poorly defined margin & 3 \\
Well defined margin & 4 \\
Stellate margin & \\
Not circumscript $(n=24)$ & 5 \\
Asymmetry and/or architectural distortion & 8 \\
Normal parenchymal pattern & 11 \\
Very dense parenchymal pattern & \\
\hline
\end{tabular}




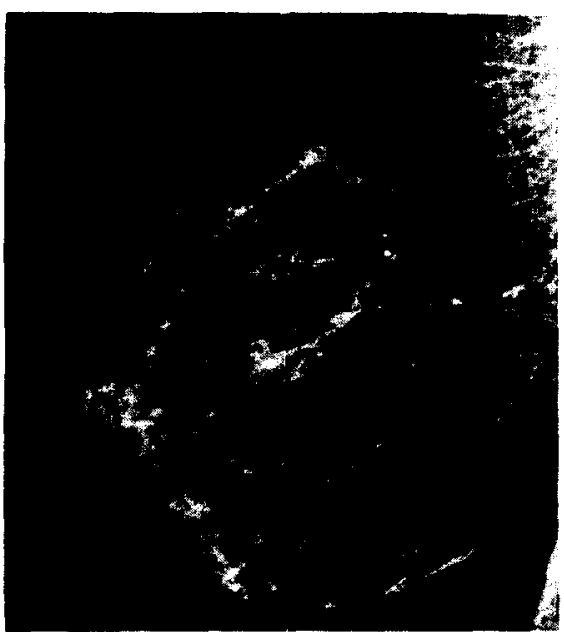

a

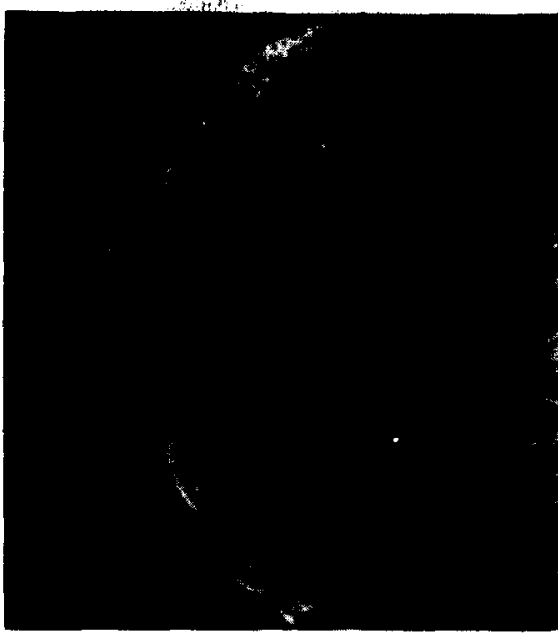

b

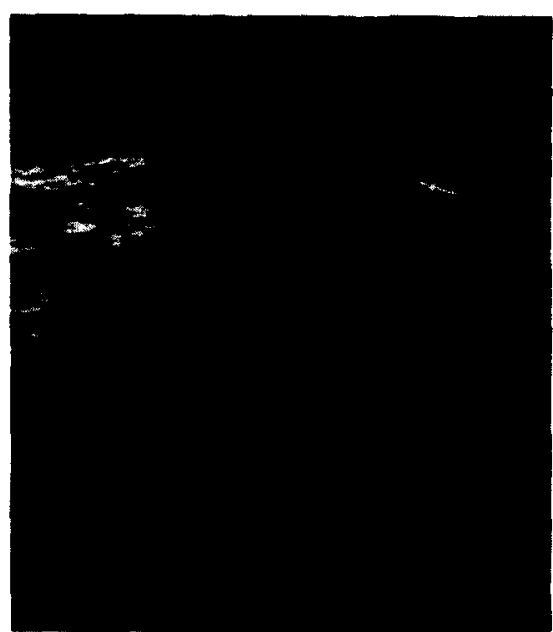

c

Fig. 2. A 59-year-old female with a palpable mass lateral to the nippie of the right breast, (a) lateral oblique, and (b) the cranio-caudal view shows a circumscript lesion with poorly defined border (arrows), (c) sonography shows a solid hypoechoic lesion with well defined borders (arrow).

\subsection{Sonography}

Sonographic characteristics are listed in Table 2. All patients had an identifiable lesion and when there was an identifiable mass on the mammograms no discrep- ancy in the location of the lesion was seen on sonography. The lesions ranged from 0.8 to $4.0 \mathrm{~cm}$ (median, 1.5), and were either well- or poorly-defined. Ovalshaped lesions were seen twice as often as round lesions.
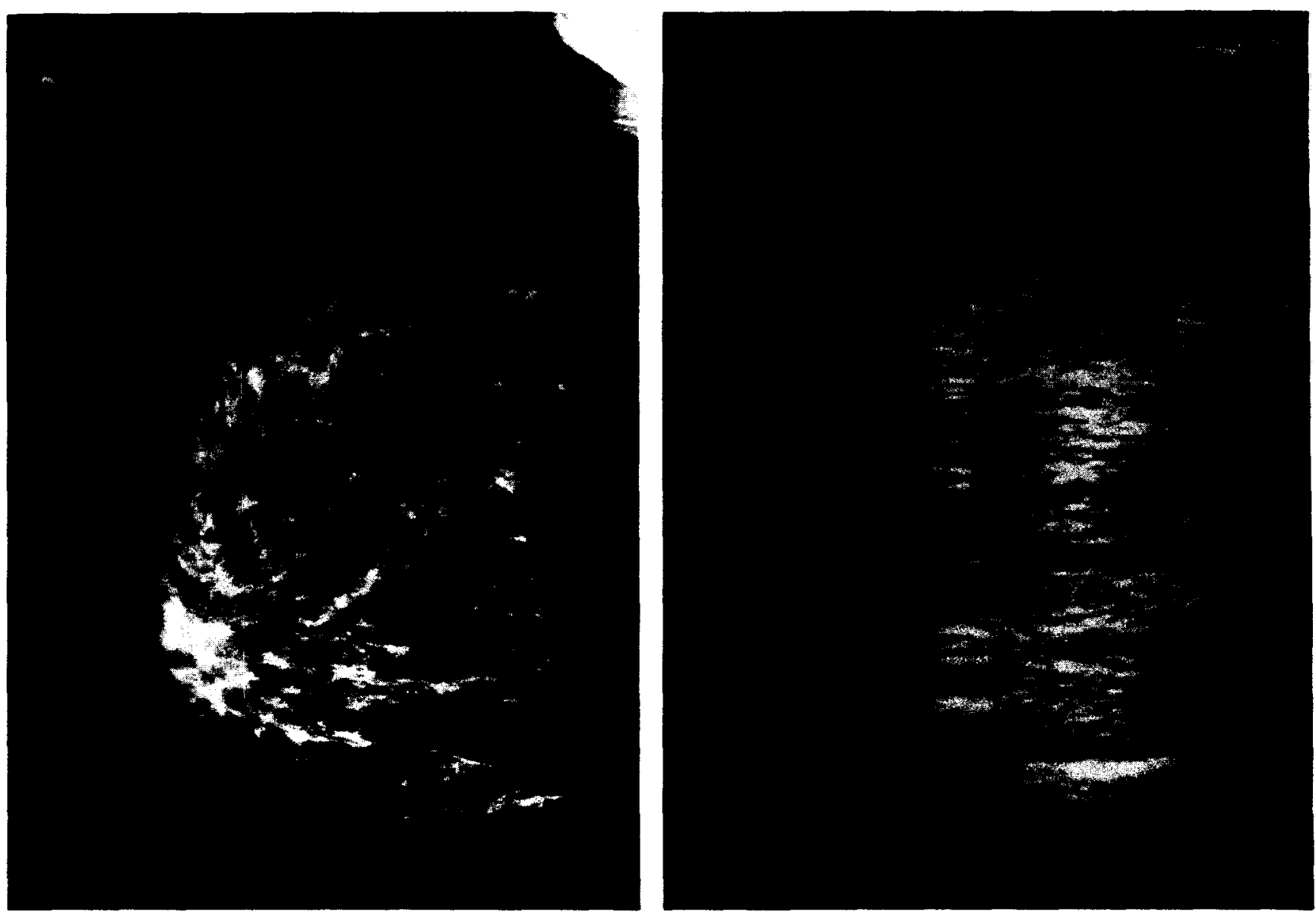

$\mathbf{a}$

Fig. 3. A 50-year-old female presented with pruritis without a palpable mass, (a) mammography shows a poorly-defined subareolar density (arrows), and (b) on sonography a cystic lesion is seen with a well-defined thickened wall. 
Table 2

Sonographic criteria of 47 cases of non-puerperal mastitis

\begin{tabular}{lc}
\hline Findings & No. of cases \\
\hline Margin & 23 \\
Well defined & 24 \\
Poorly defined & 15 \\
Shape & 30 \\
$\quad$ Round & 2 \\
Oval & \\
Stellate & 7 \\
Echogenicity & 24 \\
Solid & 16 \\
Cyst & 5 \\
$\quad$ Combination & \\
Ductectasia & \\
\hline
\end{tabular}

Although the majority of the lesions were cystic, solid components were observed on ultrasound in $50 \%$ of the patients (Fig. 2b). In cystic lesions internal echoes or thickened walls as a sign of infection were seen in 54\% of the patients (Fig. 3), the remaining cysts lacked internal echoes. Posterior shadowing was not observed. Ductectasia was observed mostly subareolarly (Fig. 4).

\subsection{Follow-up}

During the follow-up period no signs of breast malignancy were observed.

\section{Discussion}

NPM is not a single specific histopathological entity, but comprises several inflammatory diseases that may develop in a (non-lactating) breast [3-6]. A variety of terms and entities has been reported to classify NPM [7]. The most frequently used classification subtypes are:

1. Subareolar abcess of the breast. A low-grade infection with a high recurrency rate, mostly affecting younger women. The pathogenesis is squamous metaplasia of the epithelium of the large milk ducts and plugging of the ducts with keratin, causing obstruction and secondary infection $[8,9]$.

2. Mastitis complicating fibrocystic disease which is often associated with nipple discharge. Stasis of breast secretion and periductal leakage incur inflammatory reaction and associated fibrosis $[10,11]$.

3. Inflammation of a cyst. Aseptic inflammation or bacterial infection of a cyst can occur occasionally [11].

4. Plasma cell mastitis, a non-bacterial inflammation in older women due to extravasation of intraductal secretion into the periductal connective tissues. Due to its asymptomatic course and the typical calcifications on mammograms, diagnostic errors, e.g. confusion with malignancy, are unlikely [4].

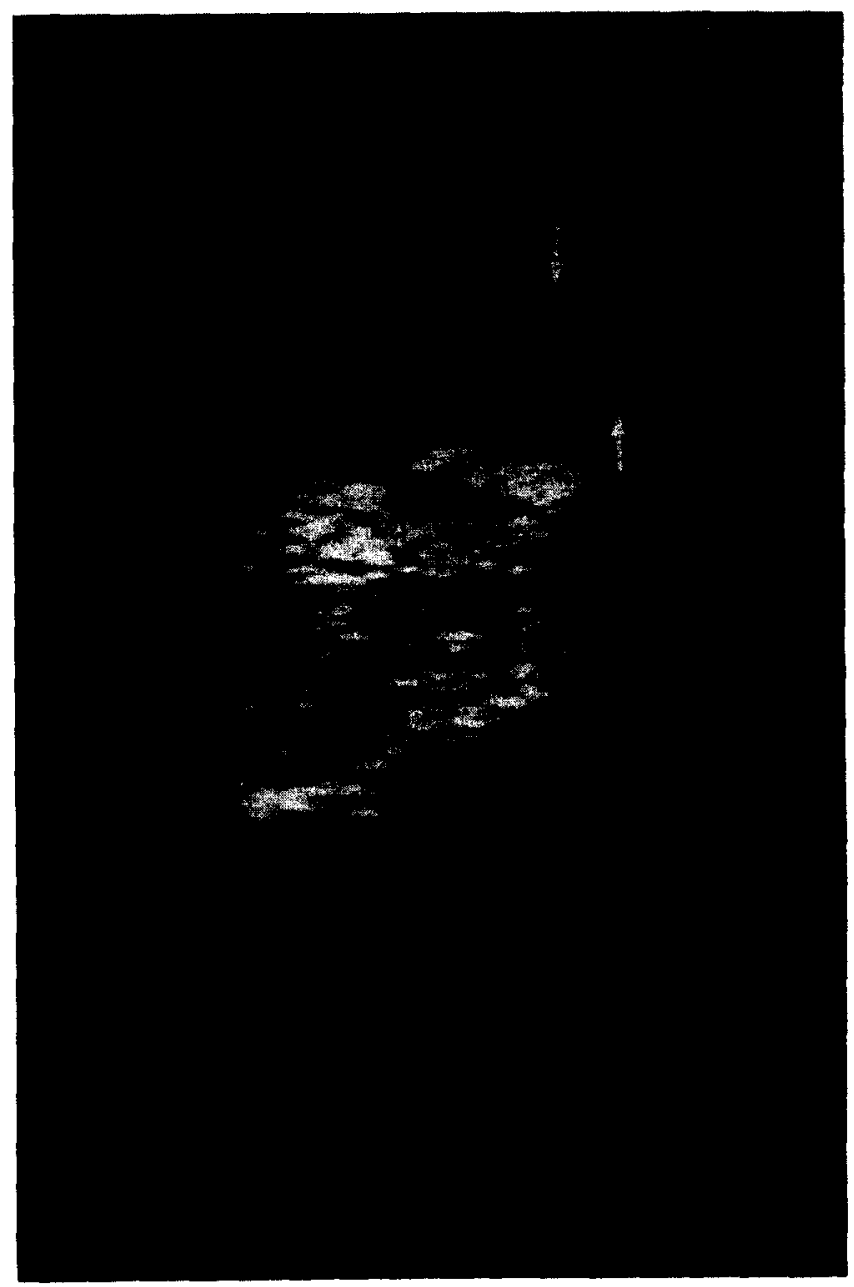

Fig. 4. A 31-year-old female presented with a palpable subareolar mass. Sonography shows a solid oval lesion with ductectasia (arrow).

In our group of patients only the classification subtypes 1-3 were observed. A cytological differentiation could not be made between subtypes 2 and 3 .

When mastitis presents as an abscess, a low- or a highdensity, circumscribed lesion with a homogeneous center is seen on mammography $[4,12,13]$. Oedema of the skin and the subcutaneous fatty tissue may be present. Especially in these cases it may be impossible to differentiate between an abscess, or infiltrating lobular carcinoma $[1,6,13]$.

In this study no specific characteristics could be found on the mammograms of patients with NPM, independent of the subtype classification. Many patients with NPM show no abnormality on mammography at all! This may be partly due to dense fibroglandular tissue in the relatively young group of patients. For that reason the use of complementary sonography in patients with palpable lesions is advocated in order to achieve more information on the parenchymal pattern. However, similar to mammography, ultrasound studies in patients with NPM also present with a variety of non-specific 
features $[1,14,15]$. Similar to mammography, well or poorly defined lesions were seen, corresponding to previous reports $[1,15,16]$.

Due to the infected contents of cysts in some patients, the lesions were sonographically interpreted as being solid. Other findings not typical for simple cysts were internal echoes, septa and thickened walls.

The location of NPM in our series was subareolar in 20 cases (Fig. 1). This may be explained by the mechanism of squamous metaplasia of large ducts and ductal plugging that causes these abscesses [8,9].

The nonspecific mammographic and sonographic characteristics in patients with NPM necessitate further diagnostic information of the lesions. Ultrasound permits FNAB of lesions as small as $5 \mathrm{~mm}$. Cytology has proven to be a useful and reliable method in diagnosing inflammatory lesions of the breast.

In conclusion, mammographic and sonographic features of NPM are nonspecific. When NPM is suspected (e.g. a subareolar location) the diagnosis should be confirmed with FNAB. This is the most sophisticated procedure that may prevent unnecessary surgical intervention in an important number of patients.

\section{References}

[I] Jackson VP. The role of US in breast imaging. Radiology 1990; 177: 305-311.

[2] van Overhagen H, Laméris JS, Berger MY et al. Assessment of distant metastases with ultrasound-guided fine needle aspiration biopsy and cytology study in carcinoma of the esophagus and gastroesophageal junction. Gastrointest Radiol 1992; 17: 305-310.
[3] van Overhagen $H$, Zonderland HM, Laméris JS. Radiodiagnostic aspects of non-puerperal mastitis. Fortschr Rontgenstr 1988; 149: 294-297.

[4] Hoeffken W, Lanyi M. Mammography. Stuttgart: Thieme, 1983.

[5] Paulus DD, Benign diseases of the breast. Radiol Clin North Am 1983: 21: 27-50.

[6] Reddin A, McCrea ES, Keramati B. Inflammatory breast disease: mammographic spectrum. South Med J 1988; 81: 981-989.

[7] Hughes LE. Non-lactional inflammation and duct ectasia. $\mathrm{Br}$ Med Bull 1991; 47: 272-283.

[8] Galblum LI, Oertel YC. Subareolar abscess of the breast: diagnosis by fine needle aspiration. Am J Clin Pathol 1983; 80: 496-499.

[9] Silverman JF, Lannin DR, Unverferth M, Norris HT. Fine needle aspiration cytology of subareolar abscess of the breast. Acta Cytol 1986; 30: 413-419.

[10] Sickles EA, Filly RA, Callen PW. Benign breast lesions: ultrasound detection and diagnosis. Radiology 1984; 151: 467-470.

[11] Peters F, Geisthovel F, Schulze-Tollert J, Pfeiderer A, Breckwoldt M. Die non-puerperale Mastitis. Disch Med Wochenschr 1985; 110: 97-103.

[12] Tabar L, Dean PB. Teaching atlas of mammography. Stuttgart: Thieme, 1983.

[13] Gold RH, Montgomery CK, Minagi H, Annes GP. The significance of mammary skin thickening in disorders other than primary carcinoma: a roentgenologic-pathologic correlation. Am J Roentgenol 1971; 112: 613-621.

[14] Hilton S, Leopold GR, Olson LK, Willson SA. Real-time breast sonography: application in 300 consecutive patients. Am J Roentgenol 1986; 147: 479-486.

[15] Hayes R, Michell M, Nunnerley HB. Acute inflammation of the breast - the role of breast ultrasound in diagnosis and management. Clin Radiol 1991; 44: 253-256.

[16] Heywang SH, Lipsit ER, Glassman LM, Thomas MA. Specificity of ultrasonography in the diagnosis of benign breast masses. J Ultrasound Med 1984; 3: 453-461. 